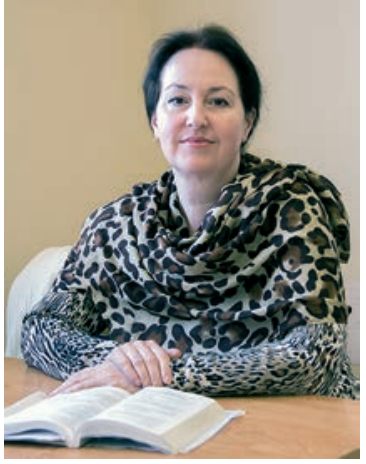

\section{Макарова Александра Стефановна}

Кандидат филологических наук, старший преподаватель

Кафедра иностранных языков, Православный Свято-

Тихоновский гуманитарный университет, 115184,

Российская Федерация, г. Москва, ул. Новокузнецкая, 23/Б, e-mail: aleste63@mail.ru

\section{Alexandra S. Makarova}

$\mathrm{PhD}$ in Philology, Senior Lecturer

Department of Foreign Languages, St. Tikhon's Orthodox University, 23/B Novokuznetskaya St., Moscow, 115184, Russian Federation, e-mail: aleste63@mail.ru

\title{
АМБИВАЛЕНТНОСТЬ ФУНКЦИОНАЛЬНОГО ПОТЕНЦИАЛА КРЫЛАТОГО ВЫРАЖЕНИЯ Я - ШАРЛИ
}

Аннотация. Фразеологический фонд национального языка изменяется одновременно с развитием общества. Образование новых устойчивых языковых единиц напрямую связано с появлением новых реалий окружающей действительности. Статья посвящена анализу функционирования крылатого выражения-неологизма французского происхождения Я - Шарли в публицистическом дискурсе и в языке интернет-пространства России. Массовость, медийность, полилоговая открытость публицистического дискурса позволяют рассматривать крылатые выражения как прекрасное средство для представления и реализации различных фразеологических инноваций. Роль массмедиа в формировании новых устойчивых оборотов огромна, так как именно медийный дискурс демонстрирует наиболее ярко реальное функционирование и жизнеспособность фрразеологических инноваций в языке. Медиадискурс имеет большое количество способов воздействия на массового адресата, и, как показывают исследования российских и зарубежных текстов, корпус крылатых выражений-галлицизмов широко применяется в языке СМИ, включая интернет-издания. Различные фразеоресурсы часто используются в сильной позиции текста - заглавии, реализуя таким образом лингвопрагматическую функцию. Анализ российского медиадискурса выявил тенденцию употребления крылатых выражений и их вариантов в сильной позиции текста, где журналисты прибегают к различным приёмам трансформации данных языковых единиц. Информационные технологии, получившие широкое распространение, позволили включать в дискурс устойчивые выражения иноязычного происхождения как в их аутентичной фрорме, так и в виде калек. Судьба крылатых выраженийлозунгов Я - Шарли / Я не Шарли в медийном дискурсе современной России и Европы свидетельствует о том, что часть крылатых выраженийгаллицизмов приобрела интернациональный статус и требует особого изучения. 
Ключевые слова. Крылатое выражение-галлицизм, лозунг, неологизм, массмедиа, публицистический дискурс, фрразеология, крылатология.

Информация о статье. Дата поступления 07 августа 2017 г.; дата принятия к печати 09 октября 2017 г.; дата онлайн-размещения 30 октября 2017 г.

\title{
AMBIVALENCE OF FUNCTIONAL POTENTIAL OF THE WINGED UNIT JE SUIS CHARLIE
}

\begin{abstract}
The phraseological fund of a national language is changing simultaneously with social development. New idioms formation is associated with new culture-specific concepts appearance. The article focuses on the analysis of functioning of the new French winged unit Je suis Charlie in the Russian journalism discourse and online language. The popularity and the media nature of journalism discourse, its implying a polylogue allow considering winged units as a perfect means of representation and implementation of different phraseological innovations. The role of mass media in new idioms formation is very important, because journalism discourse clearly shows the real functioning and vitality of new phraseological innovations in a language. The mass media discourse has many methods to influence the audience, and, as many Russian and foreign texts' analysis confirms the corpus of Gallicism winged units is widely used in the media language including internet publications. Different phraseological units are often used in the «strong position» in the text, i.e. in titles and headlines fulfilling the linguopragmatic function. The analysis of the Russian media discourse has revealed the tendency of the journalists' using winged units and their variants in the "strong position» of the text, where the journalists use different techniques of transforming these linguistic units. Information technologies, which are widely used nowadays, allowed including foreign winged units in the Russian discourse both in their authentic form and as calques. The usage of the winged units Je suis Charlie / Je ne suis pas Charlie in the Russian and European media discourse stands for the fact that some of Gallicism winged units have become international and require further studying.
\end{abstract}

Keywords. Gallicism winged unit, neologism, slogan, transformation, mass media, journalism discourse, phraseology, krylatology.

Article info. Received August 07, 2017; accepted October 09, 2017; available online October 30, 2017.

\section{Постановка проблемы}

Конец XX - начало XXI веков это благодатное время для исследований формирования фонда крылатых выражений (далее КВ). В отечественной лингвистике традиционно сложилось так, что крылатые единицы (крылатые выражения и крылатые слова) находятся на перифрерии фрразеологической системы, так как у фрразеологов нет единого мнения об объёме фразеологического фонда языка (узкое vs широкое). С позиции узкого понимания к фразеологии относятся устойчивые словесные сочетания и фразеологические единицы языка. Сторонники этого фразеологического направления (Н. Н. Амосова, М. М. Бахтин, А. М. Бабкин, В. П. Жуков, А. И. Молотков и др.) относят к фрразеологизмам КВ с общим переносным, ме- 
тафрорическим значением: секрет Полишинеля, синяя птица, солдат удачи и пр. Их оппоненты, придерживающиеся широкого понимания фразеологии (В. Л. Архангельский, С. Г. Гаврин, А. М. Григораш, Л.П.Дядечко, А. Г. Назарян, Л. И. Ройзензон, В. Н. Телия, Н. М. Шанский, С. Г. Шулежкова и др.), склонны считать объектом фрразеологического изучения любого рода устойчивые словесные комплексы (термин Л. И. Ройзензона). Данную мысль прекрасно сформулировала В. Н. Телия: «Фразеология в соответствии с различием фразеологизмов-идиом, фразеологических сочетаний и устойчивых фраз (пословиц, крылатых слов и других фразеологизмов-предложений) многими исследователями делится на фразеологию в узком смысле, исследующую фрразеологизмы-идиомы и фразеологические сочетания, прежде всего связанные значения слов, и через них смыкающуюся с лексикологией, и на фразеологию в широком смысле, изучающую и устойчивые фразы разных структурных типов, обладающие различными семиотическими функциями (единицы фольклора, фрагменты художественных текстов, формулы приветствия и т. п.)» [1, с. 560].

В нашем исследовании мы рассматриваем КВ как фразеологическую микросистему, которая имеет характерные отличительные признаки. С. Г. Шулежкова выделяет их пять: 1) связь с источником; 2) раздельнооформленность; 3) воспроизводимость; 4) устойчивость компонентного состава и грамматической структуры; 5) стабильность, устойчивость семантики, закреплённой за данным оборотом в языковом узусе [2, c. 28-29].
Художественная литература и публицистика - главные источники появления КВ, о чём свидетельствуют лексикографические и фразеографические справочники. История и культура Франции сыграли огромную роль в становлении и развитии европейской и мировой культуры. Многие сферы человеческой деятельности в той или иной мере связаны с наследием французской философии, литературы, искусства, истории, политики. Изречения великих фрилософов и просветителей, энциклопедистов и писателей, полководцев, политических и государственных деятелей закреплялись в сознании людей разных стран, оказывали влияние на формирование лингвокультуры этих народов, образовывая общий для литературных языков пласт - международный фразеологический фонд. Немалую часть данного фонда составляют КВ-галлицизмы [3, с. 35-36].

Следует напомнить, что «<..> фронд крылатых единиц (КЕ) $<\ldots>$ государственного языка России, содержит немало КВ лозунгового характера. До недавнего времени этот пласт КВ не подвергался детальному лингвистическому анализу, что связано с историей становления крылатологии как особого раздела языкознания» [4, с. 66]. Посредством языка, который является главным инструментом коммуникации, осуществляется воздействие на массовое сознание, а «лозунг один из актуальнейших жанров языкового существования» [5, с. 33] и «одно из действенных публицистических средств, используемых в современных российских СМИ» $[6$, с. 57]. По мнению многих лингвистов, КВ-лозунги представляют собой од- 
но из «важнейших фразеологических средств отражения политической жизни» [7, с. 46], так как, обладая интертекстуальными характеристиками, лозунги имеют такой отличительный признак как «крылатость», которая содержит соотнесённость с автором / источником, породившим то или иное выражение.

Сегодня процесс медиатизации всех сфер общественной жизни сказывается не только на объёме речетворчества, но и на самих медиатекстах, которые умело и оперативно интегрируют новые возможности современной технологии: появление интернет-версий традиционных СМИ, блоги, онлайновые медиа, социальные сети и т. д. Таким образом, в наш век информационных технологий первое место по активности и силе информационного влияния на общество занимают массмедиа и Интернет, динамичное развитие которого «превратило этот новый канал коммуникации в ключевое средство общения, распространения и обмена информацией» [8, с. 13].

\section{Методология}

Проведённый анализ базируется на эмпирическом материале, взятом из медийных интернет-ресурсов, что ни в коей мере не умаляет значимости печатных СМИ. В отобранных контекстах дана характеристика амбивалентности функционального потенциала КВ-лозунга Je suis Charlie (Я - Шарли) и его трансформов (термин В. М. Мокиенко) с учётом хронологического аспекта, который влияет на семантическую актуальность КВ-галлицизма. Скорость обмена информацией и яркая визуальная образность, будучи главными средствами воздействия на читателя и притягивающие его внимание к тому или иному медиатексту, приводят к тому, что «вербальный текст замещается мультимедийным, его словесная составляющая иллюстрируется, дополняется, многократно усиливается медийным компонентом - рисунком, фотографией, видеорядом, особым шрифтом и т. д.» [8, с. 14]. Одним из приоритетных исследовательских направлений современной лингвистики является изучение «поведения» фрразеосредств языка в публицистическом дискурсе, отличающимся соединением вербальных и медийных компонентов.

\section{Анализ материала}

Предмет данной статьи - KBгаллицизм Je suis Charlie (Я Шарли), которое является одним из самых ярких и распространённых КВ-лозунгов в современной публицистике и интернет-пространстве России и Европы. Однако сегодня процесс вхождения КВ французского происхождения в русский язык нельзя назвать активным. Вместе с тем значимость или трагичность события даёт повод к рождению новых устойчивых оборотов. Данное КВ пришло из фрранцузского медиадискурса в 2015 г. и мгновенно вошло во многие языки в аутентичной форме. Напомним, что через несколько часов после теракта в редакции французского сатирического еженедельника «Charlie Hebdo» возобновил работу его сайт, на единственной странице которого была надпись «Je suis Charlie», выполненная белыми буквами на чёрном фоне и переведённая на семь языков: персидский, немецкий, испанский, словацкий, чешский, араб- 
ский, русский ${ }^{1}$. Автором выражения Je suis Charlie считается фрранцузский дизайнер, художественный директор журнала «Stylist» Йоахим Ронсан (фр. Joachim Roncin). С этим лозунгом европейцы вышли на демонстрации в знак протеста против расстрела террористами журналистов и полицейских 7 января 2015 г. Вскоре КВ-неологизм Je suis Charlie было подхвачено разными медийными ресурсами, символизируя единение, солидарность, поддержку. Со временем в русском языке начала параллельно употребляться калька КВ-галлицизма Я - Шарли. Несмотря на «молодость» КВ уже зафиксировано лексикографически в недавно вышедшем Словаре современных политических лозунгов России и Германии под редакцией С. Г. Шулежковой:

«Я - Шарли - универсальная формула выражения солидарности или протеста против любой несправедливости» [9, с. 238].

Однако нельзя не сказать, что авторство инварианта, породившего КВ-галлицизм Je suis Charlie, принадлежит другому человеку. В Берлине В 1963 г. американский президент Джон Фицджеральд Кеннеди произнёс по-немецки фрразу «/ch bin ein Berliner!» (Я - берлинец!), ставшую знаменитой. Подтверждение данного фракта - фриксация КВ в 2008 г. во французском словаре Jean-Fransois Guédon, Hélène Sorez Citations de culture générale expliquées [10].

Представляется интересным факт практически одновременного возникновения как КВ Je suis Charlie, так и его трансформа Je ne suis pas

${ }^{1}$ Википедия. URL : https://ru.wikipedia. org/wiki/Je_suis_Charlie (29.05.2017).
Charlie: оба датируются 07.01.2015 г. Если первое (белые буквы на чёрном фоне) было опубликовано на официальном сайте журнала «Шарли Эбдо», то второе (белые буквы на чёрном фоне с отрицанием пе и pas красного цвета) - на сайте канадской газеты «Le Huffington Post» (Квебек) $)^{2}$. Такая реакция говорит о полярности взглядов, убеждений, мнений международного журналистского корпуса на проблему толерантности в многонациональном и многоконфессиональном мире, что проявилось в амбивалентности функционирования КВ-неологизма. Анализ материалов, посвящённых означенной проблематике, свидетельствует о том, что мировое сообщество, как и российское, разделилось на тех, кто одобряет позицию журнала «Шарли Эбдо», выходя с лозунгом Я - Шарли, и тех, кто её не поддерживает.

Способность КВ расширять сочетаемость основной структуры с новыми компонентами и легко «врастать» в любой контекст особенно широко используется в языке СМИ. Процесс преобразования КВлозунга Я - Шарли также активен: «...лозунг может употребляться как в форме полукальки, так и в исконном французском обличье, но чаще в трансорормированном виде» [9, c. 238]. Таким образом, появление трансформов данного КВ-лозунга, из которых наиболее востребованным оказался Je ne suis pas Charlie (Я не Шарли), доказывает не только фракт его продуктивности, но и актуальную роль как фразеологического ре-

${ }^{2}$ Le Huffington Post. URL: http://quebec.huffingtonpost.ca/2015/01/08/je-nesuis-pas-charlie-mouvement-a-contre-courant_n_6431688.html (20.02.2017). 
сурса языка. Сравните: Я - Шарли; Я - Беслан; Я - Луганск, но Я не Шарли!; "Je Suis Guantanamo», "Je Suis Gaza»; Ho Je ne suis pas Charlie; Charlie I am Not и пр.

Выступая в роли заголовка, КВгаллицизм Я - Шарли и особенно его трансформ Я не Шарли оказываются более эфффективными текстообразующими средствами, чем любая другая языковая единица, а «<..> в общепринятой в наше время публицистической "битве за умы” читателя роль актуальной фразеологии сложно переоценить, так как её функция безусловного аргумента рождается фактически на глазах читателя и подкрепляется эфффектом совместной с автором публикации памяти о неких фоновых событиях <...>, а для читателя <...> аргумент подкрепляется ещё и "узнаваемостью" данной неофраземы как излюбленного прецедентного акцента» [11, с. 77]. Таким образом, чем более КВ-лозунги известны максимальному количеству носителей языка, тем более они действенны, так как это «<... “культурнознаковые" интертекстуальные высказывания, которые опираются на общность универсалий - социальных, культурных или языковых - фоновых знаний автора и читателя» [12, с. 117].

Перейдём к анализу примеров употребления КВ-лозунга, в котором будем придерживаться хронологии появления публикаций в российском современном медийном дискурсе. Данный метод позволяет увидеть изменения взглядов и оценок на лозунг в российском обществе через призму приёмов его трансформаций.

В первом заглавии обнаруживается инвариант КВ:

"Я - Шарли»: мир скорбит по убитым в Париже
Минутой молчания почтили память погибших соотечественников миллионы французов. В Париже траур ознаменовался звоном колоколов в знаменитом Нотр-Дам де Пари. В Нанте, Тулузе, Лионе и многих других городах сотни тысяч жителей замерли в минуте скорби: или на улицах и площадях - на акциях в знак солидарности с журналистами «Шарли Эбдо», - или просто там, где их застал этот полдень: на остановках, железнодорожных станциях, в метро, в магазинах ${ }^{3}$.

В публикации от 08.01.2015 г., то есть, появившейся на следующий день после теракта в редакции еженедельника Шарли Эбдо, КВ-лозунг, занимая сильную позицию текста, стоит в начале заголовка и выделен графически кавычками. Выражение является частью сложного бессоюзного предложения, оно содержит не только информацию о событии, но и оценку события. Вторая часть заголовка мир скорбит по убитым в Париже актуализирует позитивную оценку, которая выражается через цитацию КВ-лозунга.

Траурный марш "Je suis Charlie» обернулся комедией позора для французских руководителей.

Президент и премьер Франции в ходе полуторамиллионного марша в честь единства нации вели себя как деmú ${ }^{4}$.

${ }^{3}$ «Я - Шарли»: мир скорбит по убитым в Париже. URL : http://www.vesti.ru/doc. html?id=2260723 (20.02.2017).

${ }^{4}$ Траурный марш «Je suis Charlie» обернулся комедией позора для французских руководителей. URL : http://www.mk.ru/politics/2015/01/11/traurnyy-marsh-je-suis-charlieobernulsya-komediey-dlya-francuzskikh-prezidenta-i-premera.html (05.05.2017). 
Здесь КВ-лозунг используется в номинативной функции, так как представляет собой название траурного марша и, поэтому выделяется автором кавычками. Лозунг употреблён в качестве иноязычного вкрапления Je suis Charlie, являясь частью заглавия и активнее привлекая внимание читателей. Данную публикацию от предыдущей отделяют всего два дня, однако заголовок уже содержит иронию, построенную на антитезе саркастического характера траурный марш - комедия позора, что свидетельствует о начале изменений отношения российского общества к политической позиции французского еженедельника.

Следующий контекст - реакция на карикатуру с утонувшим сирийским мальчиком, опубликованную в «Шарли Эбдо» в сентябре 2015 г.:

"Я не Шарли»: соцсети ополчились на Charlie Hebdo за карикатуру с утонувшим ребенкомбеженцем

Новая провокация глобального маситаба от еженедельника Charlie Hebdo вызвала шквал критики во всем мире. За карикатуру на утонувшего трехлетнего сирийца на издание ополчились даже те, кто яростно защищал журналистов после атаки террористов ${ }^{5}$.

Представленное заглавие содержит не инвариант КВ-лозунга, а его трансформ «Я не Шарли», которое проявляет себя как оптимальное средство для воздействия на читателя. Изменённое на противоположное значение трансформа актуализируется в контексте словами

${ }^{5}$ «Я не Шарли»: соцсети ополчились на Charlie Hebdo за карикатуру с утонувшим ребенком-беженцем. URL : http://www.ntv.ru/ novosti/1522978/ (13.02.2017). с семантикой агрессии: ополчились на Charlie Hebdo, новая провокация глобального масштаба, вызвала шквал критики.

В представленной ниже публикации В. Познер высказывается более определённо, называя карикатуру кощунством:

Владимир Познер: «Кто сегодня скажет: "Je suis Charlie»? Я точно не скажу!»

А что бы сказал Вольтер по поводу этих карикатур? Ведь это тоже своего рода высказывание. И когда семерых работников этого журнала убили исламские экстремисты за публикацию карикатур на пророка Мухаммеда, вся Франция встала на дыбы, на защиту свободы слова. Вся Франция вышла с лозунгом "Јe suis Charlie» («Я -Шарли»), и я гордился Францией и фрраниузами. Кто сегодня скажет: «Je suis Charlie»? Я точно не скажу!

Имеют право рисовать такие карикатуры? Да, имеют, с точки зрения юридической, с точки зрения конституции. А вот с точки зрения просто человеческой, по-моему, нет, по-моему, не имеют. Это кощунство 6.

Данное употребление ярко демонстрирует, что КВ-лозунг является не только номинативной единицей, но и оценочно-экспрессивной, реализуя таким образом единство рационального и эмоционального в контексте. В языке современных СМИ «широко представлено публичное осуждение, а порой и разоблачение деятельности, взглядов, мнений чаще всего известных лиц» [13, с.

${ }^{6}$ Владимир Познер: «Кто сегодня скажет: «Је suis Charlie»? Я точно не скажу!» // Познер Online. URL : http://pozneronline. ru/2015/11/12821/ (05.05.2017). 
171]. Как замечают исследователи, источники негативной оценки - это ежедневные события в мире во всех cферах жизни общества, которые дают толчок к активизации творческой деятельности публицистов, блогеров и пр.

В следующем примере автор дистанцируется от позиции французских журналистов, употребляя трансформ КВ-лозунга:

«Я не Шарли, я Су-24»: читатели RT восхитились стихотворением о гибели российского бомбардировщика7 .

Здесь наблюдается комплексное преобразование: по линии утверждения-отрицания, из простого предложения в сложное бессоюзное и субституция базового компонента инварианта Шарли на Су-24. Данные преобразования приводят к изменению семантики и нанизыванию КВ-трансформов, что создаёт насыщенный фрразеоконтекст, реализуя таким образом лингвопрагматическую функцию лозунга.

Последний контекст содержит приём полной деформации КВ-лозунга и датируется апрелем 2017 г. Причина появления данной публикации - теракт в метро СанктПетербурга:

Без всяких «шарли»: сможет ли Путин ответить на теракт в петербургском метро

Пока Владимир Путин на медиафоруме вспоминал байки про Черномырдина, в петербургском метро разорвало вагон взрывом, унесшим десяток жизней. Om президента будут ждать ответа, но

${ }^{7}$ «Я не Шарли, я Су-24»: читатели RT восхитились стихотворением о гибели российского бомбардировщика. URL : https:// russian.rt.com/ (20.12.2016). ответ здесь придумать практически невозможно.

Поясним, что при приёме полной деформации «отдельные компоненты <...> могут употребляться обособленно, не вступая в синтаксические связи, или употребляются в качестве смысловых центров сочетаний, коренным образом отличающихся структурой и лексическим составом от исходной» языковой единицы [14, с. 26]. От лозунга остался один стержневой компонент шарли, являющийся семантическим осколком или семантическим конденсатом (термин Е. И. Селиверстовой), в котором сконцентрирован весь смысл КВ-галлицизма. Вместе с тем данный компонент КВ входит в название самого еженедельника. Приём закавычивания отсылает нас к источнику появления КВ-лозунга и помогает узнать его даже в таком трансформированном виде, хотя перевод инварианта с французского на русский язык на сайте еженедельника выглядел как «Я - Шарли Эбдо», а не «Я - Шарли». Употребление имени собственного с маленькой буквы «выводит это понятие из ряда имён собственных, и оно становится именем нарицательным» [15, с. 9], символизируя таким образом тех, кто поддерживает отсутствие границ свободы. Введение местоимённого прилагательного всякий придаёт уничижительный оттенок заголовку, выносит негативную оценку, соединяя два феномена: название журнала и лозунг. Лозунг ассоциируется у современных людей с активной, порой навязываемой политической

\footnotetext{
${ }^{8}$ Без всяких «шарли»: сможет ли Путин ответить на теракт в петербургском метро. URL : https://www.dp.ru/a/2017/04/03/Bez_ vsjakih_sharli_smozhe (05.05.2017).
} 
пропагандой. Чтобы уйти от подобных откровенных штампов журналист использует приём полной деформации и делает очевидной связь между событиями в Париже в 2015 г. и в Санкт-Петербурге в 2017 г. — это теракт. Данный пример показывает, что КВ-трансформы являются одними из востребованных и массово эксплуатируемых фрразеосредств в современных медийных ресурсах, которые являются «чрезвычайно продуктивной областью для выявления актуальных в современном <...> языке механизмов смыслообразования» [11, с. 67].

\section{Выводы}

Для языка современных массмедиа характерно тиражирование авторских высказываний, что является проявлением интертекстуальности КВ и КВ-лозунгов в частности. Приём закавычивания, который обнаружен во всех рассмотренных заголовках и контекстах, придаёт авторитетность публикации и отсылает к источнику. Этим фрормальным способом автор «как бы «ограждает» себя, <...> но при этом указывает, что это «чужой» текст (графическая маркированность и указание на источник высказывания)» [16, с. 179]. Учитывая «молодость» КВ-галлицизма Je suis Charlie, память читателя vs пользователя Интернета сохраняет правильную ассоциацию и с событием, породившим лозунг - терактом в Париже, и с источником его появления - сайтом еженедельника «Шарли Эбдо».

Отмечается высокая частотность функционирования КВ-галлицизма с момента его появления в медийном пространстве России. Данный фракт может рассматриваться как причина возникновения на базе КВинварианта фразеологической серийности по модели «Я - Х» и «Я не X», где компоненты Я и X заменяются лексемами с другим значением. Например: Я - Донбасс!; «Я Волноваха»; «Я - Мариуполь»; Я не Шарли. Я - ОДЕССА! Горловка, Пески, Луганск; «Мы не Шарли!»; «Мы все - Шарли»; «Мы все - протестанты из Славянска» и т. д. [9, c. 239-240].

Анализ функционирования КВнеологизмов Я - Шарли и Я не Шарли в российском публицистическом и медийном дискурсе отражает творческую, созидательную «деятельность перестраивающегося языкового сознания, его приспособление к новым ценностно-смысловым приоритетам» [17, с. 227], что говорит об особой номинативной реакции языка на стремительные, порой трагические изменения в социокультурном пространстве общества.

Современные массмедиа, являясь полигоном для разного рода языковых экспериментов, предоставляют фактически неограниченные возможности для того, «чтобы показать реальное функционирование, жизнеспособность инноваций в речи» [18, с. 36]. Исследования последних лет подтверждают то, что продуктивный потенциал КВ так же высок, как и у безымянных фразеологизмов. Однако дальнейшее изучение КВ, в том числе и КВ лозунгового типа, «поможет постичь глубинные возможности систем языков-доноров, чьи единицы перешагнули национальные границы, и языков-реципиентов, обогащающихся за счёт творчески освоенных заимствований» [4, с. 72]. 


\section{СПИСОК ИСПОЛЬЗОВАННОЙ ЛИТЕРАТУРЫ}

1. Телия В. Н. Фразеология / В. Н. Телия // Языкознание: большой энцикл. словарь / гл. ред.: В. Н. Ярцева. - 2-е изд. - М. : Большая Российская энциклопедия, 1998. C. $560-561$.

2. Шулежкова С. Г. Крылатые выражения русского языка, их источники и развитие / С. Г. Шулежкова. - М. : Азбуковник, 2002. - 288 с.

3. Макарова А. С. Особенности фрункционирования крылатых выражений-галлицизмов в современной французской и российской публицистике : дис. ... канд. филлол. наук : 10.02 .20 / А. С. Макарова. - М., 2016. - 250 с.

4. Шулежкова С. Г. Крылатые выражения французского происхождения в интернациональном блоке лозунгов современной Европы / С. Г. Шулежкова, А. С. Макарова // Вестник РУДН. Серия «Теория языка. Семиотика. Семантика». - 2016. - № 4. - С. 65-73.

5. Вальтер Х. Лозунг как речевой жанр публицистического дискурса / Х. Вальтер // Медиалингвистика. - 2016. - № 3. - С. 33-45.

6. Шулежкова С. Г. Лозунги как публицистическое средство современных российских СМИ. Их тематика и истоки / С. Г. Шулежкова // Медиалингвистика. - 2016. № 3. - С. 57-66.

7. Зыкова Е. И. Интернет-лозунги как эфффективное языковое средство современного публицистического дискурса России / Е. И. Зыкова // Германия - Россия: вербальные и визуальные средства современного публицистического дискурса : сб. тр. конф. / под ред. Х. Вальтера ; Грайфсвальдский ун-т им. Эрнста Морица Арндта. - Грайфсвальд, 2016. - C. 46-49.

8. Добросклонская Т. Г. Методы анализа видео-вербальных текстов / Т. Г. Добросклонская // Медиалингвистика. - 2016. - № 2. - С. 13-25.

9. Дайте миру шанс! : словарь современных политических лозунгов России и Германии / под ред. С. Г. Шулежковой, А. А. Осиповой ; Грайфсвальдский ун-т им. Эрнста Морица Арндта. - Магнитогорск : Магнитогорский Дом печати, 2016. - 300 c.

10. Guédon J.-F., Sorez H. Citations de culture générale expliquées. Paris, Groupe Eyrolles, 2008. 158 p.

11. Семененко Н. Н. Дискурсивное смыслообразование в аспекте варьирования актуальной фразеосемантики (на материале интернет-публикаций) / Н. Н. Семененко // Медиалингвистика. - 2016. - № 3. - С. 67-80.

12. Макарова А. С. Теория интертекстуальности в современном языкознании / А. С. Макарова // Диалог культур и обществ / под ред. B. Afeltowicz, J. MiturskaBojanowska, H. Walter. - Szczecin, 2016. - C. 115-120.

13. Рацибурская Л. В. Новообразования в СМИ как средство выражения социальной оценки / Л. В. Рацибурская // Активные процессы в современной лексике и фрразеологии : материалы междунар. конф. 8-9 июня 2007 г. - М. ; Ярославль : Ремдер, 2007. - С. $171-175$.

14. Мелерович А. М. Фразеологизмы в русской речи : словарь: ок. 1000 единиц / А. М. Мелерович, В. М. Мокиенко. - 2-е изд., стер. - М. : Русские словари : Астрель, 2001. - 853 c.

15. Арифулин В. Н. Россия в «зеркале»: анализ лексики отдельных статей немецкого журнала «DER SPIGEL» о России за 2015 год / В. Н. Арифулин // Германия - Россия: Вербальные и визуальные средства современного публицистического дискурса. Грайфсвальд : Изд-во Грайфсвальд. ун-та им. Эрнста Морица Арндта, 2016. - С. 7-11.

16. Ломакина О. В. Паремии в контексте: способы экспликации коммуникативного намерения (на материале текстологии Л.Н. Толстого) / О. В. Ломакина // Вестник Новгородского государственного университета. Серия: Филологические науки. - 2014. № 77. - С. 177-180.

17. Алефиренко Н. Ф. Фразеология и паремиология : учеб. пособие / Н. Ф. Алефиренко, Н. Н. Семененко. - М. : Флинта : Наука, 2009. - 344 с.

18. Воронцова Ю. А. Авторские высказывания как источник прецедентных текстов / Ю. А. Воронцова // Активные процессы в современной лексике и фразеологии : материалы междунар. конф. 8-9 июня 2007 г. - М. ; Ярославль : Ремдер, 2007. — С. 36-39. 


\section{REFERENCES}

1. Teliya V. N. Phraseology. In Yartseva V. N. (ed.) Yazykoznanie: bol'shoi entsiklopedicheskii slovar' [Linguistics: Big Encyclopedic Dictionary]. $2^{\text {nd }}$ ed. Moscow, Bol'shaya Rossiiskaya entsiklopediya Publ., 1998. pp. 560-561. (In Russian).

2. Shulezhkova S. G. Krylatye vyrazheniya russkogo yazyka, ikh istochniki i razvitie [Winged Units of the Russian Language, their Sources and Development]. Moscow, Azbukovnik Publ., 2002. 288 p.

3. Makarova A. S. Osobennosti funktsionirovaniya krylatykh vyrazhenii-gallitsizmov v sovremennoi frantsuzskoi i rossiiskoi publitsistike. Kand. Diss. [The Peculiarities of Winged Units Functioning in Modern French and Russian Journalism. Cand. Diss.]. Moscow, 2016. 250 p.

4. Shulezhkova S. G., Makarova A. S. French winged units in the international block of slogans of modern Europe and Russia. Vestnik Rossiiskogo universiteta druzhby narodov. Seriy "Teoriya yazyka. Semiotika. Semantika» = RUDN Journal of Language Studies, Semiotics and Semantics, 2016, no. 4, pp. 65-73. (In Russian).

5. Val'ter Kh. Slogans as a speech genre of mass media discourse. Medialingvistika $=$ Media Linguistics, 2016, no. 3, pp. 33-45. (In Russian).

6. Shulezhkova S. G. Slogans as the publicistic means of modern mass media in Russia. Their themes and sources. Medialingvistika = Media Linguistics, 2016, no. 3, pp. 57-66. (In Russian).

7. Zykova E. I. Internet Slogans as an Effective Linguistic Means of Modern Russian Journalism Discourse. In Val'ter Kh. (ed.). Germaniya - Rossiya: verbal'nye i vizual'nye sredstva sovremennogo publitsisticheskogo diskursa [Germany - Russia: Verbal and Visual Means of Modern Journalism Discourse]. Greifswald, Graifsval'dskii universitet im. Ernsta Moritsa Arndta Publ., 2016, pp. 46-49. (In Russian).

8. Dobrosklonskaya T. G. Methods of analyzing video-verbal texts. Medialingvistika $=$ Media Linguistics, 2016, no. 2, pp. 13-25. (In Russian).

9. Shulezhkova S. G., Osipova A. A. (eds.) Daite miru shans! Slovar' sovremennykh politicheskikh lozungov Rossii i Germanii [Give the World a Chance! Dictionary of Modern Russian and German Political Slogans]. Magnitogorsk, Magnitogorskii Dom pechati Publ., 2016. 300 p.

10. Guédon J.-F., Sorez H. Citations de culture générale expliquées. Paris, Groupe Eyrolles, 2008. $158 \mathrm{p}$.

11. Semenenko N. N. Discursive meaning-making in terms of variation of actual phrasesemantic (based on the Internet publications). Medialingvistika = Media Linguistics, 2016, no. 3, pp. 67-80. (In Russian).

12. Makarova A. S. The Theory of Intertextuality in Modern Linguistics. In Afeltowicz B., Miturska-Bojanowska J., Walter H. (eds.). Dialog kul'tur i obshchestv [Dialogue among Cultures and Societies]. Szczecin, 2016, pp. 115-120.

13. Ratsiburskaya L. V. Neologisms in the Media as a Means of Expressing a Social Evaluation. Aktivnye protsessy $v$ sovremennoi leksike i frazeologii. Materialy mezhdunarodnoi konferentsii, Moskva, 8-9 iyunya 2007 g. [Active Processes in Modern Lexis and Phraseology. Papers of the International Conference of 8-9 June 2007]. Moscow, Remder Publ., 2007, pp. 171-175. (In Russian).

14. Melerovich A. M., Mokienko V. M. Frazeologizmy v russkoi rechi. Slovar': ok. 1000 edinits [Phraseological Units in Spoken Russian. Dictionary of approx. 1000 Units]. 2nd ed. Moscow, Russkie slovari Publ., Astrel' Publ., 2001. 853 p.

15. Arifulin V. N. Russia in "The Mirror»: Analyzing Vocabulary Used in Some Articles about Russia from the 2015 German Magazine «DER SPIEGEL». In Germaniya - Rossiya: Verbal'nye $i$ vizual'nye sredstva sovremennogo publitsisticheskogo diskursa [Germany Russia: Verbal and Visual Means of Modern Journalism Discourse]. Greifswald, Graifsval'dskii universitet imeni Ernsta Moritsa Arndta Publ., 2016, pp. 7-11. (In Russian).

16. Lomakina O. V. Proverbs within a context: the means of communicative intention explication (as exemplified in L.N.Tolstoy's textology). Vestnik Novgorodskogo gosudarstvennogo universiteta. Seriya: Filologicheskie nauki = Vestnik of Yaroslav the Wise Novgorod State University. Series: Philological Sciences, 2014, no. 77, pp. 177-180. (In Russian). 
17. Alefirenko N. F., Semenenko N. N. Frazeologiya i paremiologiya [Phraseology and Paremiology]. Moscow, Flinta Publ., Nauka Publ., 2009. 344 p.

18. Vorontsova Yu. A. Authors' Utterances as a Source of Precedent Texts. Aktivnye protsessy $v$ sovremennoi leksike $i$ frazeologii. Materialy mezhdunarodnoi konferentsii, Moskva, 8-9 iyunya 2007 g. [Active Processes in Modern Lexis and Phraseology. Papers of the International Conference of 8-9 June 2007]. Moscow, Yaroslavl, Remder Publ., 2007, pp. 36-39. (In Russian).

\section{ДЛЯ ЦИТИРОВАНИЯ}

Макарова А. С. Амбивалентность функционального потенциала крылатого выражения Я - Шарли / А. С. Макарова // Вопросы теории и практики журналистики. - 2017. T. 6, № 4. — C. 566-577. DOI: 10.17150/2308-6203.2017.6(4).566-577.

\section{FOR CITATION}

Makarova A. S. Ambivalence of Functional Potential of the Winged Unit Je Suis Charlie. Voprosy teorii i praktiki zhurnalistiki = Theoretical and Practical Issues of Journalism, 2017, vol. 6, no. 4, pp. 566-577. DOI: 10.17150/2308-6203.2017.6(4).566-577. (In Russian). 